\title{
Different destination, different commuting pattern? Analyzing the influence of the campus location on commuting
}

\author{
David S. Vale (corresponding author) \\ University of Lisbon \\ dvale@fa.ulisboa.pt
}

\author{
Claudia M. Viana \\ University of Lisbon \\ claudiaviana@campus.ul.pt
}

\author{
Mauro Pereira \\ University of Lisbon \\ mauro.pereira@fa.ulisboa.pt
}

\begin{abstract}
There is a vast literature on the relationship between built environment and travel, emphasizing the importance of built environment as a determinant of travel. However, the majority of studies focuses on the characteristics of origins and neglects the influence that the destination might have on travel, despite the already demonstrated importance of destinations to explain travel. In this paper, we test the relationship between residential and workplace built environment and the commuting pattern of staff and students of the University of Lisbon, a multi-campus university. Data was obtained through a dedicated travel survey, containing 1474 georeferenced individuals. Chi-square analyses were developed to analyze differences between staff and students and between different campuses. A logistic regression model was developed to explain car commuting, controlling for socio-demographic data. Two different models were developed for students and staff.

Our results show the built environment and associated multimodal accessibility of the campuses are important explanatory variables of commuting. Free parking at the campus is crucial for car commuting, especially for students. These results emphasize the importance of measuring destinations as explanatory variables and promoting good urban integration of the campus in the city, increasing its multimodal accessibility.
\end{abstract}

Keywords: University campus, commuting, destination, student, staff

\section{$1 \quad$ Introduction}

There is a vast literature on the relationship between the built environment and travel, emphasizing the importance of the built environment as a determinant of travel. In general terms, the determinants of

Copyright 2018 David S. Vale, Mauro Pereira \& Claudia M. Viana

http://dx.doi.org/10.5198/jtlu.2018.893

ISSN: 1938-7849 | Licensed under the Creative Commons Attribution - Noncommercial License 3.0

The Journal of Transport and Land Use is the official journal of the World Society for Transport and Land Use (WSTLUR) and is published and sponsored by the University of Minnesota Center for Transportation Studies. This paper is also published with additional sponsorship from WSTLUR. 
the built environment can be described as the 5Ds (Cervero \& Kockelman, 1997; Cervero, Sarmiento, Jacoby, Gomez, \& Neiman, 2009; Ewing \& Cervero, 2010), better defined as “3Ds+A", i.e., Density, Diversity, Design and Accessibility, the last normally identified as Destination Accessibility and Distance to transit (Vale \& Pereira, 2016). However, the focus of the majority of studies is on the characteristics of origins (the location of the home) and they neglect the influence that the destination might have on travel, despite the already demonstrated importance of destinations in explaining travel.

Indeed, the built environment of destinations has been pointed out as more important than the built environment of origins in explaining mobility patterns for several travel modes (Forsyth, Hearst, Oakes, \& Schmitz, 2008; McNeil, 2011; Millward, Spinney, \& Scott, 2013; Vale \& Pereira, 2016), especially if the destination is a regular, consistent destination such as the workplace (Chatman, 2003). Even for active travel, this influence still holds (Manaugh \& El-Geneidy, 2011), as although the home to work distance is the major barrier to active commuting, the workplace is an origin for several other daily trips (Dong, Ma, \& Broach, 2015), and its built environment features might impede or encourage the making of these trips by walking or cycling (Adams, Bull, \& Foster, 2016). The uncertain geographical context problem (Kwan, 2012) gives further support to the importance of destinations in explaining travel behavior, since spatiotemporal variability is extremely important in understanding the real exposure of an individual throughout the day, not only to air pollution and associated health risks (Park \& Kwan, 2017), but also to different space-time accessibility conditions (Miller, 2007; Weber \& Kwan, 2002), which might exert a strong influence on mode choice and associated travel behavior.

University campuses are special and important destinations in cities. Not only do they constitute important landmarks in cities and exert an important cultural and educational influence, they are also large employers, generating a significant number of trips (Lavery, Páez, \& Kanaroglou, 2013; Shannon et al., 2006; Tolley, 1996). Therefore, like other similar places such as hospitals and office and science parks, they can play an important role in promoting sustainable urban mobility for students and staff (Akar \& Clifton, 2009; Balsas, 2003) as well as contribute health benefits, such as reduced depression (Field, Diego, \& Sanders, 2001) and decreased risk of overweight and obesity (Frank, Andresen, \& Schmid, 2004).

Additionally, the complex and distinctive travel behavior of university students who commute for three or more years to the same place, and are potential active commuters given their age and income situation, is well known (Delmelle \& Delmelle, 2012; Limanond, Butsingkorn, \& Chermkhunthod, 2011; Miralles-Guasch \& Domene, 2010; Zhou, 2012). Students participate more in social or recreational activities than the general population, making more daily trips (Khattak, Wang, Son, \& Agnello, 2011). In contrast, researchers, professors and administrative staff, like other full-time workers, acquire travel habits that affect their mode choice and frequency (Heinen, van Wee, \& Maat, 2010), normally associated with a greater dependency on private vehicles and longer commutes (Shannon et al., 2006; Zhou, 2014).

Previous research studied universities sited at different locations throughout the world (Limanond et al., 2011; Miralles-Guasch \& Domene, 2010; Rodríguez \& Joo, 2004) and results consistently point out that the built environment in which they are located, together with the parking policy of the campus, can be determinant in promoting active travel (Rodríguez \& Joo, 2004; Wang, Akar, \& Guldmann, 2015; Whalen, Páez, \& Carrasco, 2013; Zhou, 2016).

In this paper, we are revisiting the influence of the university's built environment and accessibility conditions on the travel pattern of students. We have used as case study the University of Lisbon, the largest university of Portugal with nearly 50,000 students distributed over 18 faculties. The university is spread across the Lisbon Metropolitan Area in nine different campuses, located in the city of Lisbon and in the suburbs, offering considerably different built environment and accessibility conditions for the 
members of each campus. Through a comparison of five urban campuses, we evaluate to what extent the travel behavior of students and staff can be explained by the built environment of the campus, regardless of the built environment of their residence.

\section{Hypothesis}

In accordance with the existent literature on the relationship between land use and travel, and on the commuting pattern of students, we are establishing two hypotheses:

a) Students and staff have a different commuting pattern, regardless of their residential place or workplace;

b) Students and staff's commuting behavior is influenced by the characteristics of the built environment of their residential location, but also by the built environment features of their university campus.

\section{$3 \quad$ Methodology}

\subsection{Travel survey}

To test our two hypotheses, we conducted a focused travel survey during December 2015, using both an online platform and a face-to-face questionnaire to obtain a significant and representative sample of all faculties of the university. All students and staff (researchers, professors and administrative staff) were invited to participate, and asked to describe their typical mobility pattern from their home to the university. We asked for the location of their house (7-digit postal code), socioeconomic data, and also some data regarding alternative mobility patterns and willingness to change travel mode (see the list of selected variables in the appendix).

We obtained 2037 valid answers, and geocoded the residential location of all individuals with $\mathrm{Ar}$ cGIS@ Online Geocoding Service, supplemented with the Portuguese postal service company website (CTT) for unmatched addresses, which reduced the geocoded sample to 1882 individuals. Finally, as we wanted to evaluate typical commuting patterns of students and staff, we selected only faculties in which we had both students and staff and also only individuals that travel to the university 3 or more times per week, which produced the final sample with 1474 individuals, 1219 students and 255 staff.

\subsection{Built environment data}

We collected built environment data for both home and workplace locations, based on the known determinants of BE for travel, namely: density, diversity, design (including connectivity), accessibility, and topography (see full list in the appendix). Due to lack of data, topography was only collected for the campuses. All built environment indicators were calculated using a 500-metre floating catchment area (FCA), calculated in ArcGIS@ Network Analyst with road centerlines. Through a correlation analysis of variables within each dimension, we selected a final list of 10 variables, as seen in Table 1 . With these, we calculated two indexes: walkability index and accessibility index. Inspired by the walkability index of Frank and colleagues (Frank et al., 2006; Frank, Devlin, Johnstone, \& van Loon, 2010; Frank, Schmid, Sallis, Chapman, \& Saelens, 2005), our walkability index was calculated after standardizing the six built environment variables, giving equal weight to all. Accessibility index was calculated after normalization of the three accessibility variables, also giving equal weight to all, and varies between 0 and 1 . Since car parking availability and cost can increase car commuting (Christiansen, Engebretsen, Fearnley, \& Usterud Hanssen, 2017), we also calculated a parking index for each campus, by calculating a dummy variable representing the availability of free parking at each campus. 
Table 1: Built environment variables used to analyze residential and campus locations

\begin{tabular}{cl}
\hline Dimension |Variable code & Description \\
\hline Built environment & \\
\hline BE_Walkability & \\
Density & Number of resident population (m2) \\
N_Resident & Number of dwellings (m2) \\
N_Dwellings & \\
Diversity & Number of points of interest (POIs) \\
NumPOIS & Variety of POIs \\
VarietyPOIS & \\
Design & Average link length (m) \\
Average_Link_Length & Pedestrian shed ratio (0 to 1) \\
Pedshed & \\
BE_Accessibility & Has a metro stop up to 500 metres (Yes=1) \\
Acc_Metro & Has a train stop up to 800 metres (Yes=1) \\
Acc_Train & Number of transit stops \\
Count_Stop & \\
\hline Parking* & Free parking spaces (Yes=1) \\
\hline FreeParking &
\end{tabular}

\subsection{Statistical and spatial analysis}

We developed three major analyses to test our hypotheses, using three dependent variables: travel mode, travel time and travel steps. First, to evaluate the differences between students and staff, we developed a chi-square analysis, to compare students' and staffs travel behavior. Second, to test for differences between campuses, we started by developing a spatial analysis of residential locations of students and staff. A kernel density function map was calculated for all campuses and for each of the campus individually, with a 100-meter cell size resolution. To control for eventual errors, we focused our analysis on only five campuses for which we had data for both students and staff. Third, we developed chi-square analyses to evaluate differences between the five campuses, and also a logistic model to explain car commuting, using a dummy variable "CarCommuting." Spatial analysis was developed with ArcGIS@ 10.3.1 and statistical analysis was developed with Statistical Package for the Social Sciences (SPSS) version 22.

Due to the known influence of travel distance on commuting, we segmented our sample into four classes of distance, reflecting active travel feasibility. Accordingly, we used "less than $1 \mathrm{~km}$," in which walking is possible, " 1 to $4 \mathrm{~km}$," in which besides walking the bicycle is the fastest mode, " 4 to $8 \mathrm{~km}$," in which walking is residual but bicycle is still feasible, and "more than $8 \mathrm{~km}$," in which only public transport or SOV are the feasible options.

\section{$4 \quad$ Results}

\subsection{Students and staff commuting pattern}

In our sample, we registered a high car ownership rate, but the ownership rate of staff (94.1\%) is higher than that of students $(88.5 \%)$ - Table 2. Similarly, almost all staff members have a driver's license (93.3\%), while only $70.2 \%$ of students have one, which is nevertheless quite high for a young population, in which $80.3 \%$ are less than 25 years old (undergraduate students). Students depend more on 
public transport, as can be seen in the $70.4 \%$ of public transport monthly ticket holders, in comparison to only $27.1 \%$ of staff.

Table 2: Socioeconomic features of the sample of staff and students

\begin{tabular}{|c|c|c|c|c|c|c|}
\hline & \multicolumn{2}{|c|}{ Staff } & \multicolumn{2}{|c|}{ Student } & \multicolumn{2}{|c|}{ Total } \\
\hline & $\mathrm{n}$ & Percent & $\mathrm{n}$ & Percent & $\mathrm{n}$ & Percent \\
\hline \multicolumn{7}{|l|}{ Socio-economic } \\
\hline \multicolumn{7}{|l|}{ SE_Gender } \\
\hline Female & 147 & 57.6 & 820 & 67.3 & 967 & 65.6 \\
\hline Male & 108 & 42.4 & 399 & 32.7 & 507 & 34.4 \\
\hline \multicolumn{7}{|l|}{ SE_Age } \\
\hline Under 25 years & 2 & 0.8 & 979 & 80.3 & 981 & 66.6 \\
\hline 25 to 34 & 28 & 11 & 150 & 12.3 & 178 & 12.1 \\
\hline 35 to 44 & 60 & 23.5 & 52 & 4.3 & 112 & 7.6 \\
\hline 45 to 54 & 91 & 35.7 & 25 & 2.1 & 116 & 7.9 \\
\hline 55 to 64 & 70 & 27.5 & 12 & 1 & 82 & 5.6 \\
\hline 65 or more & 4 & 1.6 & 1 & 0.1 & 5 & 0.3 \\
\hline \multicolumn{7}{|l|}{ SE_HasCar } \\
\hline No & 15 & 5.9 & 140 & 11.5 & 155 & 10.5 \\
\hline Yes & 240 & 94.1 & 1079 & 88.5 & 1319 & 89.5 \\
\hline \multicolumn{7}{|l|}{ SE_DriversLicense } \\
\hline Yes & 238 & 93.3 & 856 & 70.2 & 1094 & 74.2 \\
\hline No & 17 & 6.7 & 363 & 29.8 & 380 & 25.8 \\
\hline \multicolumn{7}{|l|}{ SE_Passe } \\
\hline Yes & 69 & 27.1 & 858 & 70.4 & 927 & 62.9 \\
\hline No & 186 & 72.9 & 361 & 29.6 & 547 & 37.1 \\
\hline Total & 255 & 100.0 & 1219 & 100.0 & 1474 & 100.0 \\
\hline
\end{tabular}


Table 3: Differences in the commuting pattern of staff and students

\begin{tabular}{|c|c|c|c|c|c|c|c|c|c|}
\hline & \multicolumn{2}{|l|}{ Staff } & \multicolumn{2}{|c|}{ Student } & \multicolumn{2}{|l|}{ Total } & \multirow[b]{2}{*}{$\mathbf{x}^{2}$} & \multirow[b]{2}{*}{ df } & \multirow[b]{2}{*}{ p-values } \\
\hline & $\mathrm{n}$ & Percent & $\mathrm{n}$ & Percent & $\mathrm{n}$ & Percent & & & \\
\hline \multicolumn{10}{|l|}{ Commuting } \\
\hline Com_Mode & & & & & & & 239.1 & 5 & 0.000 \\
\hline Walk & 22 & 8.6 & 176 & 14.4 & 198 & 13.4 & & & \\
\hline Bicycle & 1 & 0.4 & 10 & 0.8 & 11 & 0.7 & & & \\
\hline Public Transport & 43 & 16.9 & 676 & 55.5 & 719 & 48.8 & & & \\
\hline Car passenger & 1 & 0.4 & 21 & 1.7 & 22 & 1.5 & & & \\
\hline SOV & 175 & 68.6 & 254 & 20.8 & 429 & 29.1 & & & \\
\hline PT + others & 13 & 5.1 & 82 & 6.7 & 95 & 6.4 & & & \\
\hline Com_Time & & & & & & & 55.48 & 5 & 0.000 \\
\hline$=<5 \mathrm{~min}$ & 1 & 0.4 & 8 & 0.7 & 9 & 0.6 & & & \\
\hline $5-15 \mathrm{~min}$ & 32 & 12.5 & 116 & 9.5 & 148 & 10.0 & & & \\
\hline $15-30 \mathrm{~min}$ & 95 & 37.3 & 275 & 22.6 & 370 & 25.1 & & & \\
\hline $3045 \mathrm{~min}$ & 66 & 25.9 & 234 & 19.2 & 300 & 20.4 & & & \\
\hline $45-60 \min$ & 26 & 10.2 & 175 & 14.4 & 201 & 13.6 & & & \\
\hline$>60 \mathrm{~min}$ & 35 & 13.7 & 411 & 33.7 & 446 & 30.3 & & & \\
\hline Com_Dteps & & & & & & & 112.4 & 6 & 0.000 \\
\hline 1 & 175 & 68.6 & 419 & 34.4 & 594 & 40.3 & & & \\
\hline 2 & 30 & 11.8 & 195 & 16 & 225 & 15.3 & & & \\
\hline 3 & 31 & 12.2 & 287 & 23.5 & 318 & 21.6 & & & \\
\hline 4 & 19 & 7.5 & 204 & 16.7 & 223 & 15.1 & & & \\
\hline 5 & 0 & 0.0 & 82 & 6.7 & 82 & 5.6 & & & \\
\hline 6 & 0 & 0.0 & 28 & 2.3 & 28 & 1.9 & & & \\
\hline 7 or more & 0 & 0.0 & 4 & 0.3 & 4 & 0.3 & & & \\
\hline Total & 255 & 100.0 & 1219 & 100.0 & 1474 & 100.0 & & & \\
\hline
\end{tabular}

Overall, the mobility pattern of staff is different from that of students. In terms of travel mode, students show a more evenly distributed pattern in all travel modes, as already pointed out in the literature (Whalen, Páez, \& Carrasco, 2013). A significant difference is found in the travel mode of staff and students $\left(\mathrm{x}^{2}(5)=239.1, \mathrm{p}=.000\right)$. Indeed, most of the students use public transport $(55.5 \%)$ or walk $(14.4 \%)$ to the university, while the vast majority of staff use SOV (68.6\%). Likewise, travel time also differs between the two groups $\left(\mathrm{x}^{2}(5)=55.48, \mathrm{p}=.000\right)$, with students showing a longer travel time than staff. Finally, the number of steps of the commuting trip, used as an indicator of the burden of the commuting, is also significantly different between the two groups $\left(\mathrm{x}^{2}(6)=112.4, \mathrm{p}=.000\right)$, with students needing more steps than staff to reach the university.

\subsection{Commuting pattern per class of distance}

Despite the difference found in the commuting patterns of students and staff, an additional feature that has a clear influence on commuting is the distance from the residential location to the university, as distance, in itself, reduces the feasibility of certain travel modes once certain thresholds are passed. Our results show that distance is an important explanatory variable for commuting, either in explaining the travel mode of staff $\left(\mathrm{x}^{2}(6)=33.92, \mathrm{p}=.000\right)$ or students $\left(\mathrm{x}^{2}(6)=395.14, \mathrm{p}=.000\right)$, or in explaining travel time $\left(\mathrm{x}^{2}(15)=113.52, \mathrm{p}=.000\right.$, and $\mathrm{x}^{2}(15)=796.12, \mathrm{p}=.000$, respectively - Table 4$)$. However, within the same travel distance class, the commuting pattern of students and staff remains different, as in the case of SOV usage by staff, which is zero in the closest travel distance zone (under $1 \mathrm{~km}$ ), but is similar across 
all other zones (around 70\%), where students' use of SOV increases with distance. In terms of walking however, the pattern is similar in both groups, being dominant in the first zone $(92.5 \%$ and $100 \%)$ and significantly decreasing as distance increases. In terms of travel time, for staff it tends to increase with distance up to the $8-\mathrm{km}$ zone, in which the majorities take up to 30 minutes to commute. After this distance threshold, 30 minute stands as the norm, which suggests that staff members are able to exchange distance for speed, maintaining their commuting within the acceptable isochrones, as already seen in Lisbon (Vale, 2013). On the other hand, students seem not to be able to keep their commuting within the acceptable value, as travel time tends to increase with travel distance, as well as with the number of steps needed to reach the university.

Table 4: Differences in commuting pattern of staff and students according to their distance from the university

\begin{tabular}{|c|c|c|c|c|c|c|c|c|c|}
\hline \multicolumn{5}{|c|}{ Staff } & \multicolumn{5}{|c|}{ Student } \\
\hline Zone 1 & Zone 2 & Zone 3 & Zone 4 & Total & Zone 1 & Zone 2 & Zone 3 & Zone 4 & Total \\
\hline$<=1 \mathrm{~km}$ & $>1$ to $<=4 \mathrm{~km}$ & $>4$ to $<=8 \mathrm{~km}$ & $>8 \mathrm{~km}$ & & $<=1 \mathrm{~km}$ & $>1$ to $<=4 \mathrm{~km}$ & $>4$ to $<=8 \mathrm{~km}$ & $>8 \mathrm{~km}$ & \\
\hline
\end{tabular}

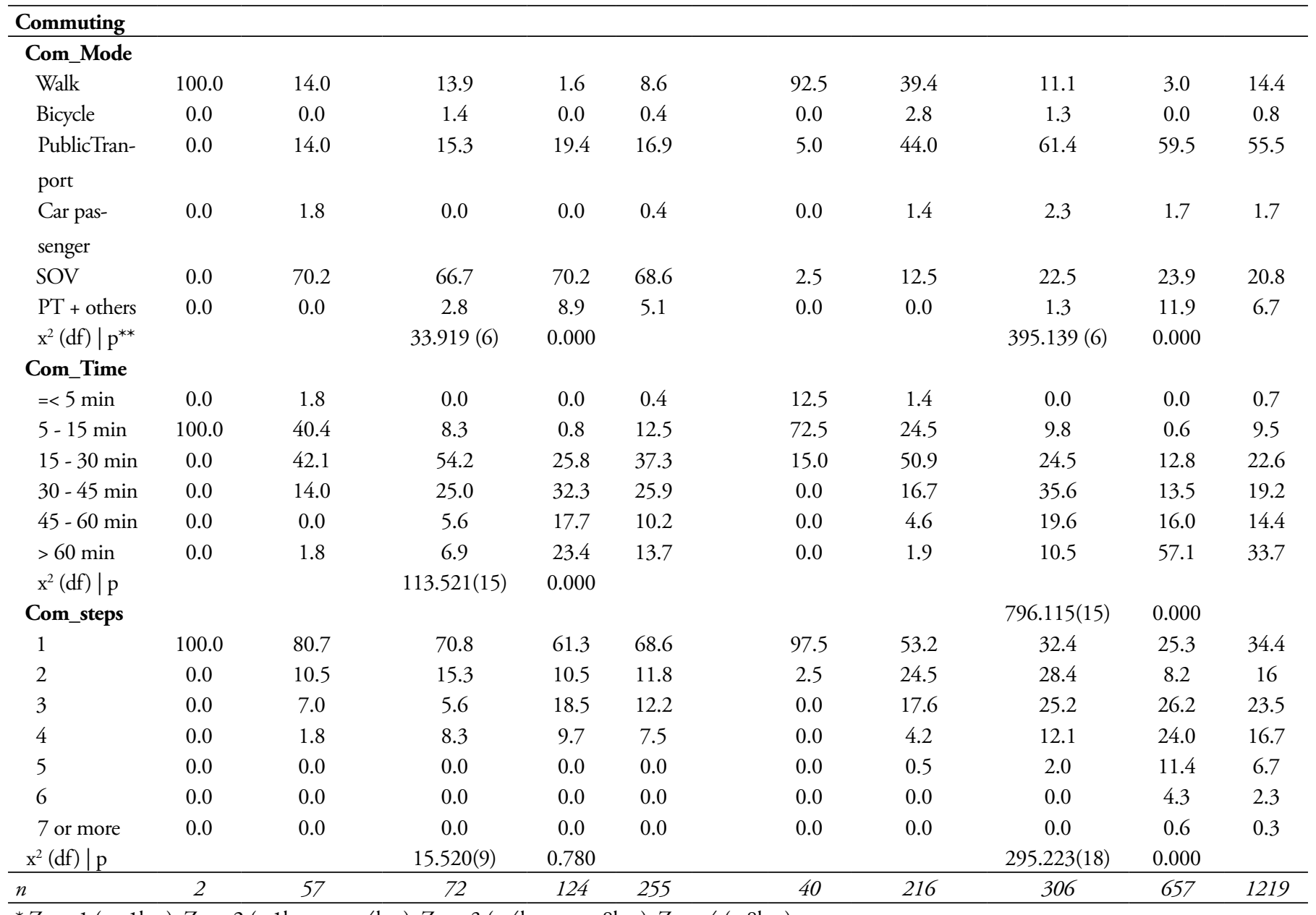

* Zone $1(<=1 \mathrm{~km})$, Zone $2(>1 \mathrm{~km}$ to $<=4 \mathrm{~km})$, Zone $3(>4 \mathrm{~km}$ to $<=8 \mathrm{~km})$, Zone $4(>8 \mathrm{~km})$

** In order to achieve viable result to $\mathrm{c} 2$ the travel mode was grouped into 3 modes: Walk/bike, PT (solo or with others) and SOV

\subsection{The influence of the campus location}

The campuses of the University of Lisbon show different built environment features - see Figure 1. The university is spread across nine campuses, located in three different municipalities: Lisbon, Oeiras and Loures. Through the use of our three indexes (walkability, accessibility, and parking availability), 
it becomes clear that they constitute four different types of campus. ISEG and IST are examples of an "urban campus," with high walkability and accessibility, and no free parking available outside the campus. Cidade Universitária is the main campus of the University and has good multimodal accessibility. However, due to its very large size (approximately 10 hectares), it shows lower walkability conditions, and we therefore classified it as a "large urban campus." Pólo da Ajuda is the secondary campus of the University, being the location of three faculties. It shows poor walkability and multimodal accessibility, and free parking is available in the campus - we classified it as a "suburban campus." Finally, FMH is a special case of a suburban campus: being the location of the sports science faculty, it is adjacent to the National Stadium of Portugal, and is therefore classified as an "isolated campus." Finally, in terms of parking, it should be said that practically all faculties have private parking for staff and sometimes also for students, available for a small monthly or annual fee, which is a clear example of the subsidization of car commuting by the University (Tolley, 1996).
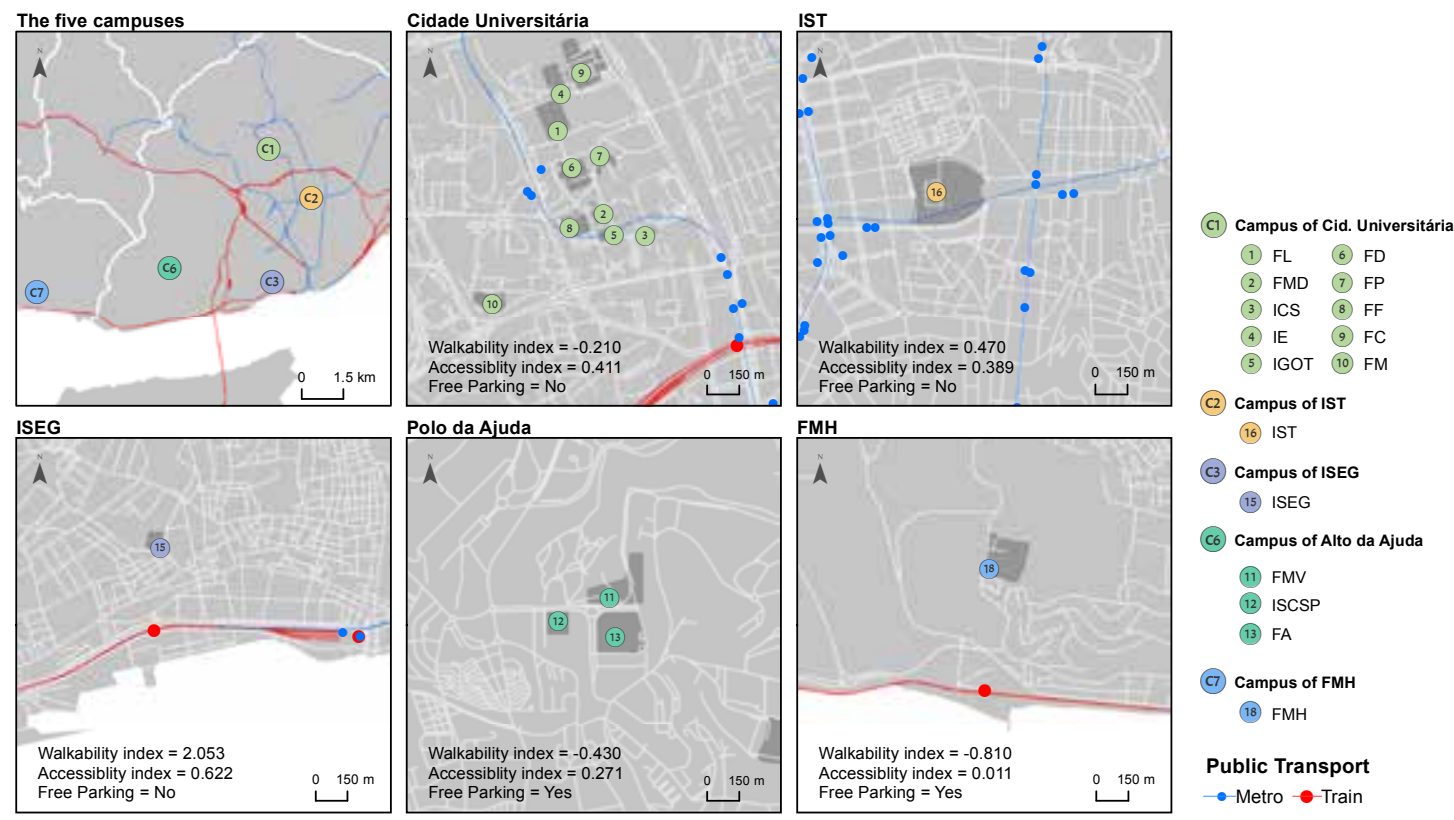

Figure 1: Location of the analyzed campuses

\subsubsection{Spatial analysis}

The kernel density map of the residential locations of staff and students shows a general location pattern that follows the main public transportation network of Lisbon, namely the metro and train lines, with a clear tendency towards the center of Lisbon as a preferred location (see Figure 2). However, different campuses show different distribution of their staff and students. The urban campuses (IST and ISEG) show a more concentrated pattern, due to the higher availability of housing nearby the campus. On the other hand, the suburban campus (Pólo da Ajuda) has its population spread across the metropolitan area, with a minor tendency towards the nearby locations. The large urban campus (Cidade Universitária) has a similar scattered pattern, although with a higher tendency for individuals to locate across the city of Lisbon, following the metro network. The isolated campus (FMH) is a special case, as several students live on campus, and so the density distribution is clearly focused on the campus itself. 

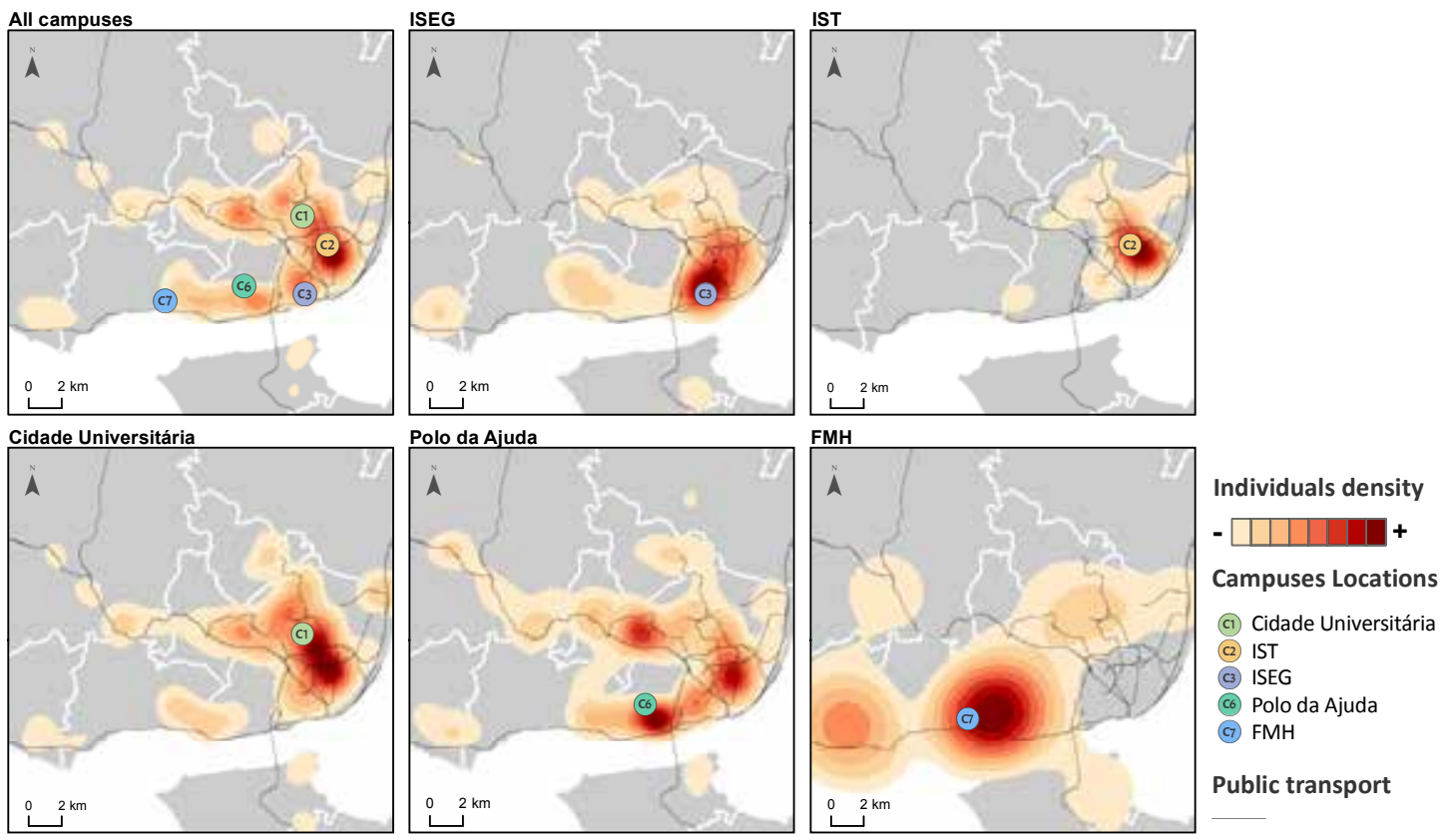

Figure 2: Kernel density maps of the residential location of staff and students of the different campuses

\subsubsection{Statistical analysis of the influence of campus location on commuting pattern}

Despite a low percentage of staff walking (8.6\%), this pattern alters according to the campus. Indeed, as seen in Table 5, the percentage of staff walking to urban campuses (IST and ISEG) is significantly higher than average, between 13.6 and $20.0 \%$. Travel time is not influenced by the location of the campus, again suggesting that staff members exchange distance for speed, choosing faster travel modes to reduce travel time. On the other hand, students are mainly public transport users (55.5\%), and only $14.4 \%$ walk to campus. Nevertheless, as in the case of staff, students are affected by the location of campus, especially in terms of walking to an urban campus (IST=29.9\% and ISEG=21.4\%). Commuting to a very large campus (Cidade Universitária $=12.3 \%$ ) or a suburban campus (Pólo da Ajuda $=11.7 \%$ ) decreases the number of students walking. The suburban campus, with low multimodal accessibility, shows a significant number of students commuting by car (Pólo da Ajuda $=22.9 \%$ ). The isolated campus $(\mathrm{FMH})$ is again a special case, showing high walking (21.7\%) and also high SOV usage $(52.2 \%)$, reflecting not only the poor multimodal accessibility, but also the existence of student accommodation on campus, which allows walking to the faculty. Just as with staff, travel time is not affected by the location of the campus. 
Table 5: Commuting pattern of staff and students by campus (\%)

\begin{tabular}{|c|c|c|c|c|c|c|c|c|c|c|c|c|}
\hline & \multicolumn{2}{|c|}{ Cidade Univ. } & \multicolumn{2}{|c|}{ Polo Ajuda } & \multicolumn{2}{|c|}{ ISEG } & \multicolumn{2}{|c|}{ IST } & \multicolumn{2}{|c|}{ FMH } & \multicolumn{2}{|c|}{ Total } \\
\hline & Staff & Student & Staff & Student & Staff & Student & Staff & Student & Staff & Student & Staff & Student \\
\hline \multicolumn{13}{|l|}{ Commuting } \\
\hline \multicolumn{13}{|l|}{ Com_Mode } \\
\hline Walk & 11.2 & 12.3 & 4.3 & 11.7 & 13.6 & 21.4 & 20.0 & 29.9 & 0.0 & 21.7 & 8.6 & 14.4 \\
\hline Bicycle & 1.0 & 1.8 & 0.0 & 0.0 & 0.0 & 0.0 & 0.0 & 4.1 & 0.0 & 0.0 & 0.4 & 0.8 \\
\hline Public Transport & 19.4 & 57.7 & 17.0 & 59.5 & 13.6 & 48.7 & 15.0 & 37.1 & 9.5 & 21.7 & 16.9 & 55.5 \\
\hline Car passenger & 0.0 & 1.5 & 1.1 & 1.7 & 0.0 & 0.0 & 0.0 & 4.1 & 0.0 & 4.3 & 0.4 & 1.7 \\
\hline SOV & 60.2 & 16.9 & 76.6 & 22.9 & 68.2 & 16.2 & 55.0 & 18.6 & 85.7 & 52.2 & 68.6 & 20.8 \\
\hline PT + others & 8.2 & 9.8 & 1.1 & 4.3 & 4.5 & 13.7 & 10.0 & 6.2 & 4.8 & 0.0 & 5.1 & 6.7 \\
\hline \multicolumn{13}{|l|}{ Com_Time } \\
\hline$=<5 \mathrm{~min}$ & 0.0 & 0.0 & 1.1 & 0.3 & 0.0 & 2.6 & 0.0 & 3.1 & 0.0 & 0.0 & 0.4 & 0.7 \\
\hline $5-15 \mathrm{~min}$ & 13.3 & 8.6 & 11.7 & 6.6 & 13.6 & 12.0 & 10.0 & 23.7 & 14.3 & 34.8 & 12.5 & 9.5 \\
\hline $15-30 \mathrm{~min}$ & 36.7 & 24.5 & 41.5 & 21.5 & 27.3 & 16.2 & 45.0 & 27.8 & 23.8 & 34.8 & 37.3 & 22.6 \\
\hline $30-45 \min$ & 28.6 & 22.7 & 21.3 & 17.2 & 31.8 & 23.9 & 20.0 & 17.5 & 33.3 & 8.7 & 25.9 & 19.2 \\
\hline $45-60 \mathrm{~min}$ & 8.2 & 12.0 & 9.6 & 15.2 & 18.2 & 14.5 & 10.0 & 17.5 & 14.3 & 8.7 & 10.2 & 14.4 \\
\hline$>60 \mathrm{~min}$ & 13.3 & 32.2 & 14.9 & 39.2 & 9.1 & 30.8 & 15.0 & 10.3 & 14.3 & 13.0 & 13.7 & 33.7 \\
\hline \multicolumn{13}{|l|}{ Com_Steps } \\
\hline 1 & 67.3 & 29.8 & 68.1 & 32.5 & 72.7 & 35.0 & 75.0 & 52.6 & 66.7 & 73.9 & 68.6 & 34.4 \\
\hline 2 & 11.2 & 15.0 & 11.7 & 17.8 & 9.1 & 12.8 & 5.0 & 13.4 & 23.8 & 4.3 & 11.8 & 16.0 \\
\hline 3 & 14.3 & 26.1 & 10.6 & 22.3 & 9.1 & 28.2 & 20.0 & 22.7 & 4.8 & 4.3 & 12.2 & 23.5 \\
\hline 4 & 7.1 & 18.1 & 9.6 & 17.4 & 9.1 & 17.1 & 0.0 & 8.2 & 4.8 & 13.0 & 7.5 & 16.7 \\
\hline 5 & 0.0 & 8.0 & 0.0 & 7.2 & 0.0 & 4.3 & 0.0 & 3.1 & 0.0 & 4.3 & 0.0 & 6.7 \\
\hline 6 & 0.0 & 2.1 & 0.0 & 2.7 & 0.0 & 2.6 & 0.0 & 0.0 & 0.0 & 0.0 & 0.0 & 2.3 \\
\hline 7 or more & 0.0 & 0.9 & 0.0 & 0.2 & 0.0 & 0.0 & 0.0 & 0.0 & 0.0 & 0.0 & 0.0 & 0.3 \\
\hline$n$ & 98 & 326 & 94 & 656 & 22 & 117 & 20 & 97 & 21 & 23 & 255 & 1219 \\
\hline
\end{tabular}

\subsection{Explaining car commuting to the University of Lisbon}

Table 6 shows the logistic models of socioeconomic and built environment variables in car commuting for staff and students. For students, we developed two different models: one for all students and the other for undergraduate students only, as these last represent the vast majority of students and are normally full-time students who do not have any type of income. For all models, the dependent variable is having commuted to the campus by car (Yes=1), either as a driver or as a passenger. All models show reasonable values of $\mathrm{R}^{2}$ (Nagelkerke): between .414 and .431. As expected, the models for staff and students show different significant predictors. Car commuting by staff is mainly explained by their status, in that being a professor increases the probability of commuting by car in comparison with other staff $(\mathrm{B}=1.693, \mathrm{p}=.000)$. As expected, the number of cars in the household is also a significant predictor $(\mathrm{B}=1.564, \mathrm{p}=.000)$. For staff, commuting distance is not a significant variable, which was expected given their modal share per commuting distance class (see Table 4). The built environment of the home is not significant in explaining the commuting patterns of staff, but the accessibility of the campus is the highest significant predictor, reducing the probability of car usage $(\mathrm{B}=-1,896, \mathrm{p}=.042)$. Therefore, for 
staff, commuting to a multimodal accessible campus significantly reduces the number of car commuters, which is an important finding for transport policy development.

The commuting pattern of students is also influenced by their socioeconomic status, namely the number of cars in their household $(\mathrm{B}=1.443, \mathrm{p}=.000)$, the size of their household $(\mathrm{B}=-.532, \mathrm{p}=.000)$, and their income - in comparison to a student with a monthly income of only $€ 500 /$ month, a student with an income of more than $€ 4000 /$ month is almost twice as likely to commute by car $(\mathrm{B}=1.970$, $\mathrm{p}=.002$ ). Younger students are less frequently car commuters than older students, probably due to their family composition, which is known to influence car usage (Delmelle \& Delmelle, 2012). Unlike staff, students' car commuting is sensitive to commuting distance and to the built environment of the home and campus. Living close to the campus reduces the probability of commuting by car $(\mathrm{B}=-2.064$, $\mathrm{p}=.076$ ), as does living in a walkable environment (Walkability index at home $\mathrm{B}=-.251, \mathrm{p}=.098$ ). In contrast, studying at a campus with free parking significantly increases their probability of commuting by $\operatorname{car}(\mathrm{B}=1.432, \mathrm{p}=.000)$. The model for undergraduate students shows only similar results to the model for the entire student population. However, in either case, two major differences arise. First, the possession of a driver's license increases the probability of commuting by $\operatorname{car}(\mathrm{B}=2.927, \mathrm{p}=.000)$. Second, the built environment of the home is not significant in explaining car commuting, only the availability of parking at the campus $(\mathrm{B}=1.444, \mathrm{p}=.000)$. 


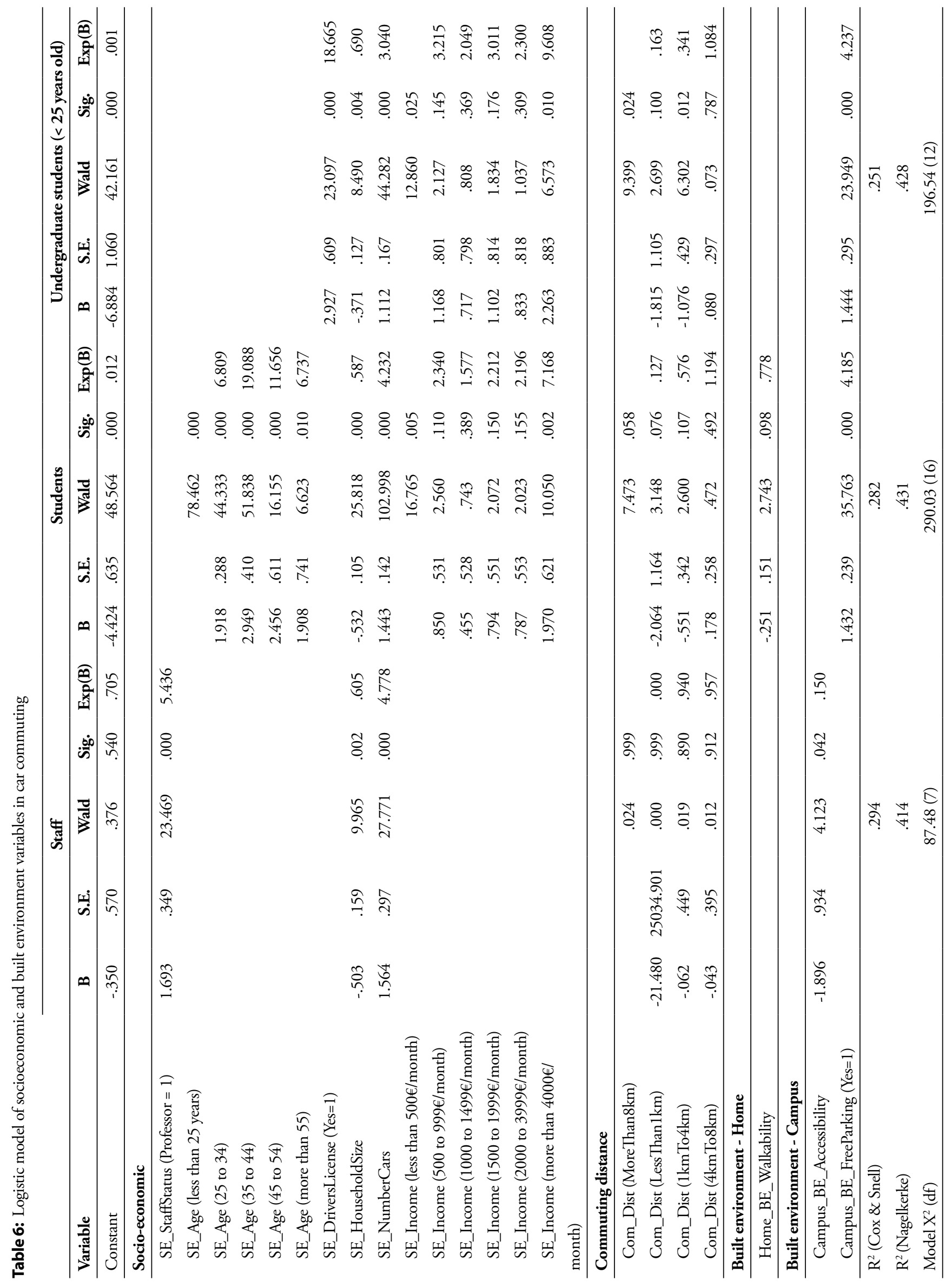




\section{Conclusion}

Our results can be instrumental in developing an effective sustainable urban mobility policy for the University of Lisbon. As expected, staff and students present different commuting patterns, and are influenced by different factors, and so different policies should be adopted for each group. Staff members are particular sensitive to the multimodal accessibility conditions of the campus, and so only through an effective "carrots and sticks" package of tools might their commuting be changed to a more sustainable pattern. In this respect, it should be said that the authors know that on a majority of campuses there is affordable parking for staff, although this data is not easily available. We assume that this could be also an influential factor in explaining the commuting behavior of staff, and intend to look deeper into this issue in the future.

Students are more influenced by the built environment of both the home and campus location. In particularly, free parking acts as a magnet for students commuting by car, despite the high financial cost of this travel mode. Parking policies are paramount in this respect, and could be one of the most effective mobility management tools for this population. Additionally, the provision of student accommodation in walkable locations might be paramount in contributing to an increase in walking and cycling to the campus, especially if these locations are close (i.e., up to $4 \mathrm{~km}$ ) to the campus.

Indeed, the observed difference in commuting patterns in relation to commuting distance supports the promotion of mixed-use development in and around campuses. Both the large urban campus and the suburban campus are good examples, in which student accommodation should be provided, as well as other local facilities. Likewise, the multimodal accessibility conditions of the campus, together with the availability of free parking, are also important policy tools. Therefore, we would recommend reducing or eliminating free parking around campuses, as long as these measures are accompanied by an increase in multimodal accessibility conditions and mixed-use development, allowing walking to be an option. In other words, one could see the campus as a special case of a Transit-oriented Development policy, in which, following Bertolini's node-place model (Bertolini, 1996, 1999; Vale, 2015), there is a significant amount of place-index that should properly be accompanied by a node-index.

We acknowledge some limitations of our work. First, due to lack of data, public transport accessibility was only poorly measured, as the distance to a stop is important, but does not fully represent the accessibility of a location. Indeed, with a better evaluation of public transport accessibility, this could eventually be an important explanatory variable. Secondly, parking was only evaluated as a binary variable representing the availability of free parking. Supported also by our own results, we acknowledge that a better evaluation of parking availability, including supply, cost, and number of places offered at the campus and in the vicinity, would provide a better representation of the real parking conditions. Finally, ideally one should measure the individual multimodal accessibility conditions, considering the home and the campus as space-time anchors. Such an evaluation would be extremely useful as an indicator of the real commuting alternatives for each individual, which again is probably an important explanatory variable. 


\section{References}

Adams, E. J., Bull, F. C., \& Foster, C. E. 2016. Are perceptions of the environment in the workplace neighbourhood associated with commuter walking? Journal of Transport and Health 3(4), 479-84. doi:10.1016/j.jth.2016.01.001

Akar, G., \& Clifton, K. J. 2009. Influence of individual perceptions and bicycle infrastructure on decision to bike. Transportation Research Record, 2140, 165-72. doi:10.3141/2140-18

Balsas, C. 2003. Sustainable transportation planning on college campuses. Transport Policy, 10(1), 3549.

Bertolini, L. 1996. Nodes and places: Complexities of railway station redevelopment. European Planning Studies, 4(3), 331-45.

Bertolini, L. 1999. Spatial development patterns and public transport: The application of an analytical model in the Netherlands. Planning Practice and Research, 14(2), 199-210.

Cervero, R., \& Kockelman, K. 1997. Travel demand and the 3Ds: Density, diversity, and design. Transportation Research Part D: Transport and Environment, 2(3), 199-219. doi:10.1016/S13619209(97)00009-6

Cervero, R., Sarmiento, O. L., Jacoby, E., Gomez, L. F., \& Neiman, A. 2009. Influences of built environments on walking and cycling: Lessons from Bogotá. International Journal of Sustainable Transportation, 3(4), 203-226. doi:10.1080/15568310802178314

Chatman, D. G. 2003. How density and mixed uses at the workplace affect personal commercial travel and commute mode choice. Transportation Research Record, 1831(1), 193-201.

Christiansen, P., Engebretsen, Ø., Fearnley, N., \& Hanssen, J. U. 2017. Parking facilities and the built environment: Impacts on travel behavior. Transportation Research Part A: Policy and Practice, 95(January), 198-206. doi:10.1016/j.tra.2016.10.025

Delmelle, E. M., \& Delmelle, E. C. 2012. Exploring spatio-temporal commuting patterns in a university environment. Transport Policy, 21(0), 1-9. doi:http://dx.doi.org/10.1016/j.tranpol.2011.12.007

Dong, H., Ma, L., \& Broach, J. 2015. Promoting sustainable travel modes for commute tours: A comparison of the effects of home and work locations and employer-provided incentives. International Journal of Sustainable Transportation, 10(6), 150106050204007. doi:10.1080/15568318.2014.100 2027

Ewing, R., \& Cervero, R. 2010. Travel and the built environment-A meta-analysis. Journal of the American Planning Association, 76(3), 265-94.

Field, T., Diego, M., \& Sanders, C. E. 2001. Exercise is positively related to adolescents' relationships and academics. Adolescence, 36(141), 104-10.

Forsyth, A., Hearst, M., Oakes, J. M., \& Schmitz, K. H. 2008. Design and destinations: Factors influencing walking and total physical activity. Urban Studies, 45, 1973-96. doi:10.1177/0042098008093386

Frank, L. D., Andresen, M. A., \& Schmid, T. L. 2004. Obesity relationships with community design, physical activity, and time spent in cars. American Journal of Preventive Medicine, 27(2), 87-96. doi:10.1016/j.amepre.2004.04.011

Frank, L. D, Devlin, A. Johnstone, S., \& van Loon, J. 2010. Neighborhood design, travel, and health in metro Vancouver: Using a walkability index. Vancouver: University of British Columbia.

Frank, L. D, Sallis, J. F., Conway, T. L., Chapman, J. E., Saelens, B. E., \& Bachman, W. 2006. Many pathways from land use to health: Associations between neighborhood walkability and active transportation, body mass index, and air quality. Journal of the American Planning Association, 72, 75-87. doi:10.1080/01944360608976725

Frank, L. D., Schmid, T. L., Sallis, J. F., Chapman, J., \& Saelens, B. E. 2005. Linking objectively mea- 
sured physical activity with objectively measured urban form: Findings from SMARTRAQ. American Journal of Preventive Medicine, 28(2S2), 117-25. doi:10.1016/j.amepre.2004.11.001

Heinen, E., van Wee, B., \& Maat, K. 2010. Commuting by bicycle: An overview of the literature. Transport Reviews, 30(1), 59-96. doi:10.1080/01441640903187001

Khattak, A., Wang, X., Son, S, \& Agnello, P. 2011. Travel by university students in Virginia. Transportation Research Record, 2255(1), 137-45. doi:10.3141/2255-15

Kwan, M.-P. 2012. The uncertain geographic context problem. Annals of the Association of American Geographers, 102(5), 958-68. doi:10.1080/00045608.2012.687349

Lavery, T. A., Páez, A., \& Kanaroglou, P. S. 2013. Driving out of choices: An investigation of transport modality in a university sample. Transportation Research Part A: Policy and Practice, 57, 37-46. doi:10.1016/j.tra.2013.09.010

Limanond, T., Butsingkorn, T., \& Chermkhunthod, C. 2011. Travel behavior of university students who live on campus: A case study of a rural university in Asia. Transport Policy, 18(1), 163-71. doi:10.1016/j.tranpol.2010.07.006

Manaugh, K., \& El-Geneidy, A. 2011. Validating walkability indices: How do different households respond to the walkability of their neighborhood? Transportation Research Part D: Transport and Environment, 16(4), 309-15. doi:10.1016/j.trd.2011.01.009

McNeil, N. 2011. Bikeability and the 20-min neighborhood: How infrastructure and destinations influence bicycle accessibility. Transportation Research Record, 2247, 53-63. doi:10.3141/2247-07

Miller, H. J. 2007. Place-based versus people-based geographic information science. Geography Compass, 1(3), 503-535.

Millward, H., Spinney, J., \& Scott, D. 2013. Active-transport walking behavior: Destinations, durations, distances. Journal of Transport Geography, 28, 101-10. doi:10.1016/j.jtrangeo.2012.11.012

Miralles-Guasch, C., \& Domene, E. 2010. Sustainable transport challenges in a suburban university: The case of the autonomous University of Barcelona. Transport Policy, 17(6), 454-463. doi:10.1016/j. tranpol.2010.04.012

Park, Y. M., \& Kwan, M. P. 2017. Individual exposure estimates may be erroneous when spatiotemporal variability of air pollution and human mobility are ignored. Health and Place, 43(February), 85-94. doi:10.1016/j.healthplace.2016.10.002

Rodríguez, D. A., \& Joo, J. 2004. The relationship between non-motorized mode choice and the local physical environment. Transportation Research Part D: Transport and Environment, 9(2), 151-73. doi:10.1016/j.trd.2003.11.001

Shannon, T., Giles-Corti, B., Pikora, T., Bulsara, M., Shilton, T., \& Bull, F. 2006. Active commuting in a university setting: Assessing commuting habits and potential for modal change. Transport Policy, 13(3), 240-253. doi:10.1016/j.tranpol.2005.11.002

Tolley, R. 1996. Green campuses: Cutting the environmental cost of commuting. Journal of Transport Geography, 4(3), 213-217. doi:http://dx.doi.org/10.1016/0966-6923(96)00022-1

Vale, D. S. 2015. Transit-oriented development, integration of land use and transport, and pedestrian accessibility: Combining node-place model with pedestrian shed ratio to evaluate and classify station areas in Lisbon. Journal of Transport Geography, 45, 70-80. doi:10.1016/j.jtrangeo.2015.04.009

Vale, D. S. 2013. Does commuting time tolerance impede sustainable urban mobility? Analyzing the impacts on commuting behavior as a result of workplace relocation to a mixed-use center in Lisbon. Journal of Transport Geography, 32, 38-48. doi:10.1016/j.jtrangeo.2013.08.003

Vale, D. S., \& Pereira, M. 2016. Influence on pedestrian commuting behavior of the built environment surrounding destinations: A structural equations modeling approach. International Journal of Sustainable Transportation, 10(8), 730-741. doi:10.1080/15568318.2016.1144836 
Wang, C.-H., Akar, G., \& Guldmann, J.-M. 2015. Do your neighbors affect your bicycling choice? A spatial probit model for bicycling to The Ohio State University. Journal of Transport Geography, 42,(January), 122-130. doi:10.1016/j.jtrangeo.2014.12.003

Weber, J., \& Kwan, M.-P. 2002. Bringing time back in: A study on the influence of travel time cariations and facility opening hours on individual accessibility. Professional Geographer, 54(2), 226-240.

Whalen, K. E., Páez, A., \& Carrasco, J. A. 2013. Mode choice of university students commuting to school and the role of active travel. Journal of Transport Geography, 31(0), 132-42. doi:http://dx.doi. org/10.1016/j.jtrangeo.2013.06.008

Zhou, J. 2012. Sustainable commute in a car-dominant city: Factors affecting alternative mode choices among university students. Transportation Research Part A: Policy and Practice, 46(7), 1013-1029. doi:10.1016/j.tra.2012.04.001

Zhou, J. 2014. From better understandings to proactive actions: Housing location and commuting mode choices among university students. Transport Policy, 33, 166-175. doi:10.1016/j.tranpol.2014.03.004

Zhou, J. 2016. Proactive sustainable university transportation? Marginal effects, intrinsic values and university students' mode choice. International Journal of Sustainable Transportation, 10(9), 815824. doi:10.1080/15568318.2016.1159357 


\section{Appendix: List of variables used}

\begin{tabular}{ll}
\hline Dimension |Variable code & Description \\
\hline Socio-economic & \\
SE_Gender & Gender (Female = 1) \\
SE_Age & Age \\
SE_HouseholdSize & Household size \\
SE_YoungChildren10_01 & Has children younger than 10 years (yes=1) \\
SE_StudentDe & Student degree (Undergraduate = 1, Master = 2, PhD = 3) \\
SE_StaffStatus & Staff type (Professor=1, Other=0) \\
SE_Income & Income \\
SE_ULyears & Number of years working/studying at University \\
SE_NumberCars & Number of cars \\
SE_HasCar & Has car (Yes=1) \\
SE_DriversLicense & Drivers licence (Yes=1) \\
SE_MonthlyTicket & Monthly ticket (Yes = 1) \\
SE_VivaViagem_01 & Rechargable PT card (Yes=1) \\
SE_PasseCost & Cost with monthly ticket \\
SE_CarCost & Cost with car usage (fuel + parking) \\
Commuting & \\
Com_Mode & Commuting mode (Walk, Bicycle, Public Transport (PT), \\
& Single occupant vehicle (SOV), car passenger, PT and other) \\
Com_Dist & Travel distance from home to the university (km) \\
Tr_Steps & Number of travel steps of the commuting trip \\
Tr_Time & Commuting time (minutes) \\
\hline
\end{tabular}




\begin{tabular}{|c|c|}
\hline Dimension | Variable code & Description \\
\hline \multicolumn{2}{|l|}{ Built environment } \\
\hline \multicolumn{2}{|l|}{ BE_Walkability } \\
\hline \multicolumn{2}{|l|}{ Density } \\
\hline N_Resident & Number of residents per area $(\mathrm{Ha})$ \\
\hline N_Buildings & Number of buildings $(\mathrm{Ha})$ \\
\hline N_Dwellings & Number of dwellings $(\mathrm{Ha})$ \\
\hline N_Exc_Res_Buildings & Number of exclusive residential buildings (Ha) \\
\hline \multicolumn{2}{|l|}{ Diversity } \\
\hline NumPOIS & Number of points of interest (POIs) per area $(\mathrm{Ha})$ \\
\hline VarietyPOIS & Variety of POIs \\
\hline \multicolumn{2}{|l|}{ Design } \\
\hline Average_Link_Length & Average link length (m) \\
\hline Node_Density & Node density (node/ha) \\
\hline Straightness & Straightness (ratio) \\
\hline Pedshed & Pedestrian shed ratio (0 to 1$)$ \\
\hline RouteLengthFCA & Route length (m) \\
\hline Count_Green* & Number of green spaces \\
\hline Area_Green* & Area of green spaces $(\mathrm{m} 2)$ \\
\hline Length_CycleLanes* & Length of bike paths (m) \\
\hline \multicolumn{2}{|l|}{ BE_Accessibility } \\
\hline Min_DistanceToStop & Distance to the closest transit stop (m) \\
\hline DistanceToStop_Type & Type of closest transit stop (BUS, metro, train) \\
\hline Acc_Metro & Has a metro stop up to 500 metres (Yes=1) \\
\hline Acc_Train & Has a train stop up to 800 metres (Yes=1) \\
\hline Acc_Bus & Has a bus stop up to 500 metres (Yes=1) \\
\hline Count_Stop & Number of transit stops \\
\hline Count_Stop_Variety & Variety of transit stops (1 to 3 ) \\
\hline \multicolumn{2}{|l|}{ Parking* } \\
\hline N_Parking & Number of parking spaces \\
\hline Paid_Parking & Paid parking spaces (Yes=1) \\
\hline FreeParking & Free parking spaces (Yes=1) \\
\hline \multicolumn{2}{|l|}{ Topography* } \\
\hline Mean_slope & Mean streat slope (\%) \\
\hline Max_slope & Maximum street slope (\%) \\
\hline Min_slope & Minimum street slope (\%) \\
\hline
\end{tabular}

